\title{
Hubungan Kesehatan Gigi dan Mulut dengan Konsep Diri Pada Remaja di SMPN 7 Pariaman
}

\author{
Deswita $^{\text {a }}$, Tiara Mayastari ${ }^{\mathrm{a}}$, Atih Rahayuningsih ${ }^{\mathrm{a}}$ \\ ${ }^{a}$ Fakultas Keperawatan Universitas Andalas \\ Korespondensi : Deswita \& Tiara Mayastari \\ E-mail :deswitapsik@yahoo.com \& a0910323050@yahoo.co.id
}

\begin{abstract}
Self concept can be influenced by any changes of physical health, the maturation, the growth, and the sociocultural process. The dental and mouth health is one of the most common health problem of adolescent. The dental and mouthcleanliness, one of the self cleanliness, is influenced the component of self concept. This studywas designed to describe the correlation between mouth health and self concept of adolescent in junior high school number 7 Pariaman using the correlation with cross sectionaldesign. The sampling technique used wastheproportionate stratified random sampling that consists of 80 participants. The data were analyzed by using the spearman correlation test. For the results of study, 66,3\% adolescentwas with unhealthy tooth and mouth, $72,5 \%$ had the positive self concept. The result of computer analysis shown the mouth health is associated to self concept of adolescent in junior high school number 7 Pariaman toward positive, moderate correlation strength, and significant $(r=0,408 ; p=0,000)$. From the result, it can be suggested that healthy service institution must make a policy about the checking of tooth and mouth healthy periodically, providing information and the impact of tooth and mouth healthy by visiting school directly.
\end{abstract}

Key words : self concept, adolescent, dental and mouth health

\begin{abstract}
Abstrak: Konsep diri dapat dipengaruhi oleh setiap perubahan yang terjadi dalam kesehatan fisik, proses matang dari kematangan, perkembangan, dan sosiokultural. Masalah kesehatan gigi dan mulut merupakan salah satu masalah kesehatan terbanyak yang dialami remaja. Kebersihan diri salah satunya kebersihan gigi dan mulut dapat mempengaruhi konsep diri. Penelitian ini bertujuan untuk mengetahui hubungan antara kesehatan gigi dan mulut dengan konsep diri pada remaja di SMPN 7 Pariaman. Jenis penelitian ini adalah korelasi dengan rancangan cross sectional. Teknik pengambilan sampel yang digunakan adalah proportionate stratified random sampling dengan jumlah responden 80 orang. Analisis data menggunakan uji korelasi spearman. Hasil penelitian didapatkan $66,3 \%$ remaja yang memiliki gigi dan mulut yang tidak sehat, $72,5 \%$ memiliki konsep diri positif. Hasil analisis mengunakan komputer menunjukan adanya hubungan kesehatan gigi dan mulut dengan konsep diri pada remaja di SMPN 7 Pariaman dengan arah positif, kekuatan korelasi sedang, dan signifikan $(\mathrm{r}=0,408 ; \mathrm{p}=0,000)$. Berdasarkan hasil penelitian ini maka disarankan kepada institusi pelayanan yang terkait agar membuat suatu kebijakan untuk melakukan pemeriksaan kesehatan gigi dan mulut secara berkala serta memberikan informasi dalam ruang lingkup kesehatan gigi dan mulut serta dampaknya dengan cara mengunjungi sekolah secara langsung.
\end{abstract}

Kata kunci : konsep diri, remaja,kesehatan gigi dan mulut 


\section{PENDAHULUAN}

Pada masa remaja terjadi perubahan fisik dan psikologis yang disebabkan oleh perubahan hormonal (Santrock, 2007). Jika pertumbuhan fisik yang dialami tidak sesuai dengan keinginannya maka remaja merasa tidak puas dengan keadaannya (Santrock, 2007).

Cara individu memandang dirinya secara utuh baik fisik, emosional, intelektual, sosial, spiritual, termasuk didalamnya adalah persepsi individu dengan orang lain maupun lingkungannya, nilai-nilai yang berkaitan dengan pengalamanan dan objek, serta tujuan harapan dan keinginannya disebut dengan konsep diri (Sunaryo, 2004). Menurut Potter \& Perry (2005); Stuart \& Sundeen (2007) komponen konsep diri meliputi gambaran diri/ citra tubuh, ideal diri, harga diri, penampilan peran, identitas diri.

Konsep diri dapat dipengaruhi oleh setiap perubahan yang terjadi dalam kesehatan fisik, proses matang dari kematangan, perkembangan, dan sosiokultural (Potter \& Perry, 2005). Saat remaja terjadi perubahan fisik dan psikologis seiring dengan pertumbuhan dan perkembangan yang dialaminya. Masalah kesehatan gigi dan mulut merupakan salah satu masalah kesehatan terbanyak yang dialami remaja (Tarwoto dkk, 2010). Kebersihan diri salah satunya kebersihan gigi dan mulut dipengaruhi oleh citra diri yang nantinya secara langsung dapat mempengaruhi komponen konsep diri lainnya (Potter \& Perry, 2005).

Masalah kesehatan gigi dan mulut yang sering dialami oleh remaja, antara lain gigi berlubang, posisi gigi yang tidak beraturan/tidak rapi, adanya pewarnaan pada gigi dan cidera pada gigi/ traumatik pada gigi (Tarwoto dkk, 2010). Menurut Wilkins (2013) dan WHO gigi dan mulut yang sehat akan memiliki karakteristik berikut: gusi tidak akan bengkak, gusi tidak meradang, akan memiliki bau minimal, tidak ada pendarahan gusi, gusi merah muda, tidak ada gigi retak, tidak ada maloklusi, tidak ada sensitivitas, tidak ada kanker mulut dan tidak ada gigi yang hilang.

Penelitian Paula dkk (2009) tentang Psychosocial Impact of Dental Esthetics on Quality of Life in Adolescents dari 301 remaja dengan rentang usia 13 sampai 20 tahun, dari sekolah umum di kota Goiania, Brasil dapat ditarik kesimpulan bahwa kesehatan gigi dan mulut tidak hanya mempengaruhi fungsi lisan dan penampilan saja, tetapi juga memiliki efek dari segi psikologis. Hasil penelitiannya yaitu adanya dampak lisan masalah gigi dan mulut yaitu menurunnya interaksi sosial karena masalah pada gigi dilaporkan oleh $88 \%$ dari remaja, dan $98,3 \%$ dari subyek menunjukkan beberapa tingkat dampak psikososial dan ketidakpuasan dengan beberapa bagian tubuh yang diungkapkan oleh $72 \%$ dari sampel.

Pemaparan diatas menggambarkan bahwa masalah kesehatan gigi dan mulut memainkan peranan penting dalam interaksi sosial dan psikologis pada remaja. Dampak kondisi kesehatan mulut terhadap kualitas hidup yaitu dapat mempengaruhi kepuasan dengan penampilan, menyebabkan perasaan malu dalam kontak sosial dan mempengaruhi efek psikologis.

Sejalan dengan hal tersebut Piovesan dkk, 2008 meneliti Oral health-related quality of life in children di Brasil pada remaja didapatkan kesimpulan lesi jaringan lunak, maloklusi, dan fluorosis gigi merupakan contoh masalah gigi umum, tetapi hanya sedikit penelitian yang difokuskan pada efek fungsional, sosial, dan emosional pada remaja. Berdasarkan pemaparan diatas, penulis tertarik untuk melakukan penelitian dengan judul hubungan kesehatan gigi dan mulut dengan konsep diri pada remaja di SMPN 7 Pariaman.

Berdasarkan latar belakang di atas dan berdasarkan hasil studi pendahuluan yang dilakukan peneliti, maka tujuan penelitian ini untuk mengetahui Hubungan Kesehatan 
Gigi dan Mulut dengan Konsep Diri pada Remaja di SMPN 7 Pariaman.

\section{METODE}

Jenis dari penelitian ini adalah korelasi dengan pendekatan cross sectional. Populasi dalam penelitian ini adalah siswa kelas VII dan VIII SMPN 7 Pariaman, yaitu sebanyak 390 orang. Teknik pengampilan sampel yang digunakan adalah proportionate stratified random sampling dengan jumlah responden penelitian sebanyak 80 orang. Pengumpulan data dilakukan selama dua hari dari tanggal 14-15 juni 2013 di SMPN 7 Pariaman, penelitian ini dimulai dari bulan februari - juli 2013. Dalam pengumpulan data, peneliti menggunakan alat ukur berupa lembaran kuisioner. Untuk mengukur kesehatan gigi dan mulut dan konsep diri digunakan kuesioner yang peneliti buat sendiri sesuai dengan indikator yang sudah ada.

Analisis data yang disajikan adalah gambaran distribusi frekuensi setiap variabel penelitian. Melalui analisis ini dapat digambarkan karakteristik dari variabel penelitian. Data diolah secara komputerisasi untuk mengetahui pengaruh variabel independen terhadap variabel dependen yang diteliti. Uji statistik yang digunakan adalah uji Spearman dengan interpretasi kemaknaan $\mathrm{p}<0,01$ serta nilai r (arah korelasi).

\section{HASIL DAN PEMBAHASAN}

Tabel 1.

Distribusi Frekuensi Data Demografi Responden di SMP N 7 Pariaman

\begin{tabular}{|c|c|c|c|}
\hline No & $\begin{array}{c}\text { Karakteristik } \\
\text { Responden }\end{array}$ & F & \% \\
\hline $\mathbf{1}$ & Umur: & & \\
& a. 13 Tahun & 21 & 26,3 \\
& b. 14 Tahun & 42 & 52,5 \\
& c. 15 Tahun & 17 & 21,3 \\
\hline & Total & 80 & 100 \\
\hline
\end{tabular}

\begin{tabular}{|c|c|c|c|}
\hline \multirow[t]{2}{*}{2} & $\begin{array}{l}\text { Jenis } \\
\quad \text { Kelamin: } \\
\text { a. Laki-laki } \\
\text { b. Perempuan }\end{array}$ & $\begin{array}{l}41 \\
39\end{array}$ & $\begin{array}{l}51,3 \\
48,8\end{array}$ \\
\hline & Total & 80 & 100 \\
\hline \multirow[t]{2}{*}{3} & $\begin{array}{l}\text { Frekuensi } \\
\text { Menggosok } \\
\text { Gigi } \\
\text { a. } \quad<2 \mathrm{x} / \text { hari } \\
\text { b. } \geq 2 \mathrm{x} / \text { hari }\end{array}$ & $\begin{array}{l}4 \\
76\end{array}$ & $\begin{array}{c}5 \\
95\end{array}$ \\
\hline & Total & 80 & 100 \\
\hline \multirow[t]{2}{*}{4} & 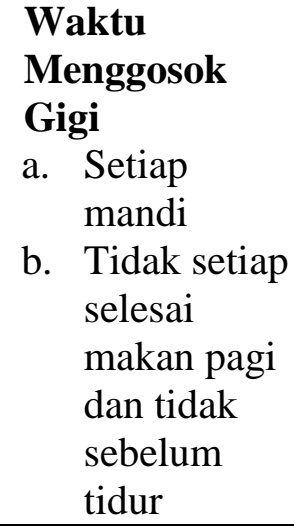 & 60 & $\begin{array}{l}25 \\
75\end{array}$ \\
\hline & Total & 80 & 100 \\
\hline
\end{tabular}

Tabel 2.

Distribusi Frekuensi Kesehatan Gigi dan Mulut pada Remaja di SMP N 7 Pariaman

\begin{tabular}{|c|l|c|c|}
\hline No & $\begin{array}{c}\text { Kesehatan } \\
\text { Gigi dan } \\
\text { Mulut }\end{array}$ & F & \% \\
\hline 1. & Sehat & 27 & 33,8 \\
\hline 2. & Tidak Sehat & 53 & 66,3 \\
\hline \multicolumn{2}{|c|}{ JUMLAH } & 80 & 100,0 \\
\hline
\end{tabular}

Hasil penelitian pada tabel 2. dapat dilihat bahwa lebih dari separuh responden memiliki gigi dan mulut yang tidak sehat yaitu $(66,3 \%)$.

Tabel 3.

Distribusi Frekuensi Konsep Diri pada Remaja di SMP N 7 Pariaman

\begin{tabular}{|c|l|c|c|}
\hline No. & Konsep Diri & F & \% \\
\hline 1. & Positif & 58 & 72,5 \\
\hline 2. & Negatif & 22 & 27,5 \\
\hline \multicolumn{2}{|c|}{ JUMLAH } & 80 & 100 \\
\hline
\end{tabular}


Hasil penelitian pada tabel 3. dapat dilihat bahwa lebih dari separuh responden memiliki konsep diri positif $(72,5 \%)$.

Tabel 4.

Hubungan Kesehatan Gigi dan Mulut dengan Konsep Diri pada Remaja di SMPN 7 Pariaman

\begin{tabular}{|c|c|c|c|c|c|}
\hline \multirow{2}{*}{$\begin{array}{c}\text { Kes } \\
\text { Gigi \& } \\
\text { Mulut }\end{array}$} & \multicolumn{2}{|c|}{ Konsep Diri } & f & p & r \\
\cline { 2 - 4 } & Positif & Negatif & & & \\
\cline { 2 - 3 } Sehat & 27 & 0 & 27 & $\mathbf{0 , 0}$ & $\mathbf{0 , 4}$ \\
\hline $\begin{array}{c}\text { Tidak } \\
\text { Sehat }\end{array}$ & 31 & 22 & 53 & $\mathbf{0 0}$ & $\mathbf{0 8}$ \\
\hline f & 58 & 22 & 80 & & \\
\hline
\end{tabular}

Hasil penelitian pada tabel 4 dapat dijelaskan bahwa dari 53 responden yang memiliki gigi dan mulut yang tidak sehat, terdapat 31 responden $(58.5 \%)$ yang memiliki konsep diri positif dan 22 responden $(41.5 \%)$ yang memiliki konsep diri negatif. Dua puluh tujuh responden yang memiliki gigi dan mulut yang sehat, terdapat 27 orang responden $(100 \%)$ memiliki konsep diri positif.

Hasil analisis pada penelitian ini didapatkan nilai $\mathrm{p}=0,000(\mathrm{p}<0,05)$ yang berarti terdapat hubungan yang bermakna antara kesehatan gigi dan mulut dengan konsep diri pada remaja. Nilai r (kekuatan korelasi) sebesar 0,408 menunjukan kekuatan korelasi antara variabel kesehatan gigi dan mulut dengan konsep diri adalah sedang dan tanda (+) menunjukkan arah korelasi yang positif, artinya semakin sehat gigi dan mulut remaja semakin positif konsep dirinya dan sebaliknya semakin tidak sehat gigi dan mulut remaja semakin negatif konsep dirinya.

Hasil analisis korelasi spearmen didapatkan nilai $\mathrm{p}=0,000(\mathrm{p}<0,05)$ yang berarti terdapat hubungan yang bermakna antara kesehatan gigi dan mulut dengan konsep diri pada remaja. Nilai r (kekuatan korelasi) sebesar 0,408 menunjukan kekuatan korelasi antara variabel kesehatan gigi dan mulut dengan konsep diri adalah sedang dan tanda (+) menunjukkan arah korelasi yang positif, artinya semakin sehat gigi dan mulut remaja semakin positif konsep dirinya dan sebaliknya semakin tidak sehat gigi dan mulut remaja semakin negatif konsep dirinya.

Hal ini sejalan dengan hasil penelitian Badran (2010) tentang The effect of malocclusion and self-perceived aesthetics on the self-esteem of a sample of Jordanian adolescents, terhadap 410 siswa (195 lakilaki dan 215 perempuan) berusia 14-16 tahun. Data yang didapatkan yaitu siswa yang membutuhkan pengobatan pada gigi memiliki rasa tidak puas dengan penampilan gigi mereka dan menghindari tersenyum untuk menyembunyikan gigi mereka. Siswa yang yang membutuhkan perawatan ortodontik, merasa estetika gigi mereka buruk dan dirasakan dampak maloklusi pada penerimaan sosial, sedangkan siswa yang telah mendapatkan perawatan ortodontik menunjukkan harga diri yang lebih tinggi daripada mereka yang tidak. Hal ini menggambarkan ketidak puasan dengan penampilan gigi memiliki efek pada konsep diri. Pemaparan diatas menggambarkan bahwa ada hubungan antara kesehatan gigi dan mulut dengan konsep diri.

Mendukung penelitian di atas Potter \& Perry (2005) mengatakan konsep diri dapat dipengaruhi oleh setiap perubahan yang terjadi dalam kesehatan fisik, proses matang dari kematangan, perkembangan, dan sosiokultural. Kebersihan diri salah satunya kebersihan gigi dan mulut dipengaruhi oleh citra diri yang nantinya secara langsung dapat mempengaruhi komponen konsep diri lainnya (Potter \& Perry, 2005). Morton (2003) mengatakan ketidak mampuan mengatur aktivitas higiene personal dapat menurunkan harga diri dan mengganggu konsep diri. Sejalan dengan hal tersebut Carpenito (2009) mengatakan kesehatan gigi dan mulut secara langsung mempengaruhi hubungan 
interpersonal yaitu penampilan, konsep diri dan komunikasi.

Berbeda dengan hal diatas pada penelitian ini ditemukan juga remaja dengan gigi dan mulut yang tidak sehat tetapi memiliki konsep diri yang positif $(58,5 \%)$. Sesuai dengan Gunarsa (2008) yang mengatakan bahwa konsep diri hanya terdapat dalam pikiran seseorang dan bukan dalam realitas yang konkrit. Jadi konsep diri tergantung dengan pribadi masingmasing, Bagaimana nilai-nilai ataupun kebiasaan yang ada dalam dirinya banyak ditentukan oleh bagaimana konsep yang dipunyainya mengenai dirinya sendiri dan pendapat mereka tentang dirinya sendiri (Gunarsa, 2008).

Penelitian ini sejalan dengan penelitian Claudino \& Traebert (2013) dengan judul Malocclusion, dental aesthetic self-perception and quality of life in a 18 to 21 year-old population pada 150 tentara Brasil berusia antara 18 dan 21 tahun di kota Tubarao, Brasil selatan didapatkan hasil bahwa bahwa individu dengan kondisi oklusi gigi buruk, memiliki persepsi diri yang buruk. Maloklusi kecil tidak menyebabkan persepsi negatif pada citra gigi, maloklusi parah akan menimbulkan penilaian negatif terhadap gigi. Hal ini dapat menggambarkan konsep diri dipengaruhi oleh seberapa besar kesehatan gigi dan mulut itu terganggu.

Hasil penelitian yang peneliti lakukan menunjukan kekuatan korelasi anatara kesehatan gigi dan mulut dengan konsep diri pada remaja di SMPN 7 Pariaman adalah 0,408 dan nilai $r$ determinannya 16,6 $\%$. Hal ini menunjukan bahwa kekuatan korelasi antara kesehatan gigi dengan konsep diri pada remaja di SMPN 7 Pariaman sedang dan sumbangan efektif kesehatan gigi dan mulut terhadap konsep diri pada remaja di SMPN 7 Pariaman sebesar $16,6 \%$. Hal ini menunjukan bahwa konsep diri remaja di SMPN 7 Pariaman dipengaruhi oleh faktor lain sebesar 83,4 $\%$. Peneliti berasumsi bahwa faktorlain yang mempengaruhi konsep diri remaja di
SMPN 7 Pariaman adalah jenis kelamin, reaksi orang lain terhadap dirinya, dukungan dari orang tua, dan keberhasilan menjalankan peran.

\section{KESIMPULAN DAN SARAN}

Dari hasil penelitian yang telah dilakukan pada remaja di SMPN 7 Pariaman, dapat disimpulkan bahwa, lebih dari separuh responden $(66,3 \%)$ memiliki gigi dan mulut yang tidak sehat dan lebih dari separuh responden memiliki konsep diri positif $(72,5 \%)$. Selain itu juga terdapat hubungan yang bermakna dengan arah positif dan kekuatan korelasi sedang antara kesehatan gigi dan mulut dengan konsep diri pada remaja di SMP N 7 Pariaman.

Disarankan agar institusi pelayanan kesehatan yang terkait membuat suatu kebijakan untuk melakukan pemeriksaan kesehatan gigi dan mulut secara berkala serta memberikan informasi dalam ruang lingkup kesehatan gigi dan mulut serta dampaknya dengan cara mengunjungi sekolah secara langsung.

\section{DAFTAR PUSTAKA}

Badran, Serene Adnan. (2010). The effect of malocclusion and self-perceived aesthetics on the self-esteem of a sample of Jordanian adolescents. Eur J Orthod, 32 (6): 638-644.

Carpenito, Lynda Juall. (2009). Diagnosis Keperawatan: Aplikasi pada Praktik Klinis. Jakarta: EGC.

Claudino, Dikson \& Traebert, Jefferson. (2013). Malocclusion, dental aesthetic self-perception and quality of life in a 18 to 21 year-old population: a cross section study. BMC Oral Health, 13 (3).

Dahlan. (2012). Statistika untuk Kedokteran dan Kesehatan : deskriptif bivariat dan multivariat dilengkapi dengan APSS dengan menggunakan SPSS. Jakarta : Salemba Medika. 
Gunarsa, Singgih. (2008). Psikologi Perkembangan anak dan remaja. Jakarta: Gunung Agung Mulia.

Morton, Patricia Gonce. (2003). Panduan Pemeriksaan Kesehatan dengan Dokumentasi Soapie. Jakarta: EGC

Paula, Delcides F. De dkk (2009).

Psychosocial Impact of Dental Esthetics on Quality of Life in Adolescents. Association with Malocclusion, Self-Image, and Oral Health-Related Issues, 79(6).

Piovesan, Chaiana dkk. (2009). Oral healthrelated quality of life in children:

Conceptual issues. Odonto Ciênc; 24 (1): 81-85.

Potter, Patricia, A \& Perry, Anne Griffin. (2005). Buku Ajar Fundamental Keperawatan. Jakarta: EGC.

Santrock, John W. (2007).Remaja, jilid 2, edisi 11. Jakarta: Erlangga.

Sunaryo. (2004). Psikologi Umum. Jakarta: EGC.

Stuart, G. W \& Sundeen, S.J. (1998). Keperawatan jiwa. Jakarta: EGC

Tarwoto dkk. (2010). Kesehatan Remaja: Problem dan Solusinya. Jakarta: Salemba Medika.

Wilkins, Esther M. (2013). Oral Health Awareness. Diakses pada tanggal 14 Mei 2013 dari http://tandemnorthwest.org/wpcontent/uploads/2013/04/DentalBooklet.pdf 